\title{
The LIM Homeodomain Factor Lhx2 Is Required for Hypothalamic Tanycyte Specification and Differentiation
}

\author{
Juan Salvatierra, ${ }^{1 \star}$ DDaniel A. Lee, ${ }^{1,6 \star}$ Cristina Zibetti, ${ }^{1}$ Maria Duran-Moreno, ${ }^{7}$-Sooyeon Yoo, ${ }^{1}$ Elizabeth A. Newman, ${ }^{1}$ \\ Hong Wang, ${ }^{1}$ Joseph L. Bedont, ${ }^{1}$ Jimmy de Melo, ${ }^{1}{ }^{-}$Ana L. Miranda-Angulo, ${ }^{1,9}$ Sara Gil-Perotin, ${ }^{7,8}$ \\ Jose Manuel Garcia-Verdugo, ${ }^{7}$ and Seth Blackshaw ${ }^{1,2,3,4,5}$ \\ ${ }^{1}$ Department of Neuroscience, ${ }^{2}$ Department of Ophthalmology, ${ }^{3}$ Department of Neurology, ${ }^{4}$ Center for High-Throughput Biology, ${ }^{5}$ Institute for Cell \\ Engineering, Johns Hopkins University School of Medicine, Baltimore, Maryland 21287, ${ }^{6}$ Department of Biology and Bioengineering, California Institute of \\ Technology, Pasadena, California 91125, ${ }^{7}$ Neuroregeneration and Multiple Sclerosis Research Unit, University of Valencia/Hospital La Fe, Valencia 46009, \\ Spain, ${ }^{8}$ Comparative Neurobiology Laboratory, Instituto Cavanilles, Centro Investigación Biomédica en Red Enfermedes Neurodegenerativas, University of \\ Valencia, Valencia 46980, Spain, and ${ }^{9}$ Institute of Medical Research, Universidad de Antioquia, Medellín, Colombia 050001
}

Hypothalamic tanycytes, a radial glial-like ependymal cell population that expresses numerous genes selectively enriched in embryonic hypothalamic progenitors and adult neural stem cells, have recently been observed to serve as a source of adult-born neurons in the mammalian brain. The genetic mechanisms that regulate the specification and maintenance of tanycyte identity are unknown, but are critical for understanding how these cells can act as adult neural progenitor cells. We observe that LIM (Lin-11, Isl-1, Mec-3)homeodomain gene $L h \times 2$ is selectively expressed in hypothalamic progenitor cells and tanycytes. To test the function of $L h x 2$ in tanycyte development, we used an intersectional genetic strategy to conditionally delete $L h x 2$ in posteroventral hypothalamic neuroepithelium, both embryonically and postnatally. We observed that tanycyte development was severely disrupted when Lhx2 function was ablated during embryonic development. $L h x 2$-deficient tanycytes lost expression of tanycyte-specific genes, such as Rax, while also displaying ectopic expression of genes specific to cuboid ependymal cells, such as Rarres2. Ultrastructural analysis revealed that mutant tanycytes exhibited a hybrid identity, retaining radial morphology while becoming multiciliated. In contrast, postnatal loss of function of $L h \times 2$ resulted only in loss of expression of tanycyte-specific genes. Using chromatin immunoprecipitation, we further showed that Lhx2 directly regulated expression of $R a x$, an essential homeodomain factor for tanycyte development. This study identifies $L h x 2$ as a key intrinsic regulator of tanycyte differentiation, sustaining Rax-dependent activation of tanycyte-specific genes while also inhibiting expression of ependymal cell-specific genes. These findings provide key insights into the transcriptional regulatory network specifying this still poorly characterized cell type.

Key words: transcription factor;; hypothalamus; metabolism; ependymal cells; radial glia; tanycytes

\section{Introduction}

Glia within the CNS, composed primarily of astrocytes, oligodendrocytes, and microglia, make crucial contributions to the formation, operation, and adaptation of diverse neural circuitries (Allen and Barres, 2009). Additional specialized glial subtypes

Received April 2, 2014; revised 0ct. 24, 2014; accepted 0ct. 29, 2014.

Author contributions: J.S., D.A.L., and S.B. designed research; J.S., D.A.L., C.Z., M.D.-M., S.Y., E.A.N., H.W., J.L.B., J.d.M., and S.B. performed research; A.L.M.-A. contributed unpublished reagents/analytic tools; J.S., D.A.L., C.Z., M.D.-M., S.Y., E.A.N., J.L.B., S.G.-P., J.M.G.-V., and S.B. analyzed data; J.S., D.A.L., and S.B. wrote the paper.

This work was supported by National Institutes of Health Grants R01EY020560 and R21NS067393. S.B. was a W.M. Keck Distinguished Young Scholar in Medical Research. M.D.-M. holds a predoctoral fellowship from the Spanish government (AP2009-4759) and S.G.-P. holds a postdoctoral fellowship (CM12/00014) from the Health Institute Carlos III. D.A.L. is a Ruth L. Kirschstein Postdoctoral Fellow (National Institutes of Health National Research Service Award F32 NS084769). We thank W. Yap, S. Aja, and members of the Blackshaw laboratory for comments on the manuscript.

The authors declare no competing financial interests.

*J.S. and D.A.L. contributed equally to this work.

Correspondence should be addressed to Seth Blackshaw at Johns Hopkins University School of Medicine, 733 North Broadway Avenue, Baltimore, MD 21287. E-mail: sblack@jhmi.edu.

DOI:10.1523/JNEUROSCI.1711-14.2014

Copyright $\odot 2014$ the authors $\quad 0270-6474 / 14 / 3316809-12 \$ 15.00 / 0$ play essential functions critical for homeostatic regulation. Notably, the ventrobasal hypothalamus, along with the retina and other circumventricular organs, are unique among adult CNS regions in retaining large numbers of radial glial-like tanycytes into adulthood, which comprise the great majority of ventricular cells (Millhouse, 1971, 1972; Rodríguez et al., 2005). These hypothalamic tanycytes regulate energy homeostasis and metabolism (Lechan and Fekete, 2007; Gao et al., 2014; Lee and Blackshaw, 2014) through multiple mechanisms. These include the detection of nutrient signals in the CSF and blood (Bolborea and Dale, 2013), control of neurohormone release (Sánchez et al., 2009), transcytosis of leptin (Balland et al., 2014), nutrient-dependent regulation of blood-brain barrier permeability (Langlet et al., 2013), and, strikingly, by acting in some cases as neural progenitor cells (Lee et al., 2012, 2013, 2014; Haan et al., 2013; Robins et al., 2013). The transcriptional regulatory network that permits tanycytes to retain these progenitor-like attributes is unknown, but is critically important to understanding the mechanisms underlying their unique plasticity.

To identify key developmental regulators of tanycyte specification and differentiation, we used an embryonic and early 
postnatal hypothalamic development gene expression atlas (Shimogori et al., 2010) to identify gene regulatory candidates. Several recent studies indicate that $L h \times 2$ may play an important role in aspects of hypothalamic development, but its potential role in tanycyte development is unknown. Both our group and others have observed robust $L h \times 2$ expression in embryonic anterior and ventrotuberal hypothalamic neuroepithelium (Porter et al., 1997; Shimogori et al., 2010; Hägglund et al., 2011; Roy et al., 2013), as well as adult hypothalamic tanycytes (Lee et al., 2012). By embryonic day (E) 15.5, Lh $x 2^{-1-}$ knock-outs show severe morphological defects in the hypothalamic median eminence (Zhao et al., 2010), a region whose structural integrity is maintained by the radial process of tanycytes. Since Lhx2 is broadly expressed (Porter et al., 1997; Shimogori et al., 2010) and $\operatorname{Lh} \times 2^{-1-}$ mice die by E15.5, the role of $\operatorname{Lh} \times 2$ in later stages of hypothalamic development has not been investigated.

We investigated the role of Lhx2 in tanycyte development using an intersectional genetic strategy to selectively delete $L h \times 2$ in the ventrobasal hypothalamic neuroepithelium. We found that neuronal specification was unaffected in these animals, but terminal differentiation of hypothalamic tanycytes was disrupted. We further observed that Lhx2 promotes tanycyte development by directly activating and maintaining expression of Rax, a homeodomain factor essential for tanycyte development (Miranda-Angulo et al., 2014). The study gives insight into how this important, but still poorly characterized, cell type is specified during development.

\section{Materials and Methods}

Animals. Pregnant CD-1 mice were obtained from Charles River Laboratories. The following mice (of either sex) were used: Foxd1-Cre and R26-tmRtmG mice were purchased from The Jackson Laboratory; Rax$C r e E R^{T 2}$ mice were generated in the corresponding author's laboratory, and are detailed in Pak et al. (2014); Lhx $2^{\text {lox/lox }}$ mice were provided by Edwin Monuki (University of California, Irvine), and GLAST-CreER ${ }^{T 2}$ mice were provided by Jeremy Nathans (Johns Hopkins University School of Medicine); Nkx2.1-Cre transgenic mice (Xu et al., 2008), which express Cre recombinase under the control of the Nkx2.1 promoter/ enhancer regions, were a generous gift from Dr. Stewart Anderson. All mice used in these studies were maintained and killed according to protocols approved by the Institutional Animal Care and Use Committee at the Johns Hopkins School of Medicine.

Tamoxifen-induced Cre activation. For the induction of Cre recombinase activity, 4-hydroxytamoxifen (4-OHT; Sigma-Aldrich) was prepared by sonicating in absolute ethanol to a concentration of $40 \mathrm{mg} / \mathrm{ml}$. Dissolved 4-OHT in ethanol was vortexed with corn oil (Sigma-Aldrich) to a final concentration of $10 \mathrm{mg} / \mathrm{ml}$, followed by evaporating of the ethanol using vacuum centrifugation. The $0.2 \mathrm{mg}$ of 4 -OHT/corn oil was intraperitoneally injected to double heterozygote $\operatorname{RaxCreER^{T2}}$ for each day from postnatal day (P) 1 to $\mathrm{P} 3$. The mice were killed at $\mathrm{P} 14$ and then used for the immunohistochemistry. GLAST-CreER ${ }^{T 2} ; \operatorname{Lh} x 2^{\text {lox/lox }}$ mice were delivered intraperitoneal tamoxifen injections for $5 \mathrm{~d}$ beginning at $\mathrm{P} 4$, receiving $1 \mathrm{mg}$ of tamoxifen on days $1-3$ and $2 \mathrm{mg}$ of tamoxifen on days 4 and 5. For both genotypes, mice were killed at P14 and processed for immunohistochemistry.

Fluorescent immunohistochemistry. Fluorescent immunohistochemistry on perfused free-floating section brain tissue was performed on cryosectioned tissue as previously described (Lee et al., 2012, 2013). Fluorescent immunohistochemistry on fresh-frozen sections (see Fig. $8 A-C$ ) were performed in the following manner: brains were quickly dissected out and frozen on dry ice in O.C.T. (optimal cutting temperature) mounting medium (Tissue-Tek, Sakura). Antibodies used in the described studies were the following: rabbit anti-GFP (1:1000; Invitrogen); chicken anti-GFP (1:500, Aves Laboratory); chicken anti-vimentin (1:1500, Millipore); rabbit anti-Sox2 (1:1500; AB5603, Millipore Bioscience Research Reagents). Double and triple staining was visualized with
Alexa Fluor 488-conjugated, Alexa Fluor 555-conjugated, Alexa Fluor 568-conjugated, Alexa Fluor 594-conjugated, or Alexa Fluor 633conjugated secondary antibodies (1:500; Invitrogen). 4',6-Diamidino-2phenylindole (DAPI) was used as a nuclear counterstain, unless otherwise noted.

All free-floating section immunohistochemical data shown was imaged and photographed on a Zeiss Meta 510 LSM confocal microscope. Fresh-frozen section immunohistochemical data was imaged and photographed on a Zeiss Axioskop-2.

In situ hybridization. In situ hybridization on fixed brain tissue (Fig. 1; see Figs. 3, $4 K-N, 6 I-B B, 8 E-J)$ was performed as described previously (Shimogori et al., 2010). In addition, in situ hybridization was performed on fresh-frozen brain tissue (Fig. 2) as previously described (Blackshaw and Snyder, 1997).

Histology. Coronal sections of the tuberal region of the hypothalamus were collected from bregma -1.28 to bregma -2.30 , and ISH analysis was matched by hypothalamic nuclei to ensure the same anatomical positions were compared. Coronal sections were collected from freshfrozen brains (unfixed) at $25 \mu \mathrm{m}$ for fresh-frozen ISH protocol (Blackshaw and Snyder, 1997). For perfused and immersion fixed brain tissue, $40 \mu \mathrm{m}$ coronal brain sections were collected and used with the perfused and immersion fixed ISH protocol (Shimogori et al., 2010).

Chromatin immunoprecipitation. CD-1 mice (Charles River) were killed at P7 according to Johns Hopkins Institutional Animal Care and Use Committee animal policies. Whole dissected hypothalami were dissociated in a collagenase I suspension, cross-linked in freshly made $1 \%$ formaldehyde, and quenched in $125 \mathrm{~mm}$ glycine. The extracted nuclei were sheared to produce $100-500 \mathrm{bp}$ range by means of probe sonication. Chromatin was immunoprecipitated by using goat anti-Lhx2 antibody (Santa Cruz Biotechnology, SC-19344-C20) or the related isotypic control (AbCam ab37373), retained on agarose beads (Invitrogen), washed, and purified by organic extraction.

The Rax regulatory regions previously identified by chromatin immunoprecipitation (ChIP)-Seq analysis of retinal tissue [unpublished; distal promoter: 7011 bp upstream of the transcription start site (TSS); proximal promoter: 2204 bp upstream of the TSS; distal sequence: 3589 bp downstream of the TTS] were evaluated for enrichment by quantitative PCR and expressed as percentage of input recovery in the treated sample over the isotypic control (see Fig. 7).

Transmission electron microscopy. Six mice (three mutant and three control animals) were perfused with $0.9 \%$ saline, followed by $2 \%$ paraformaldehyde (PFA) and 2.5\% glutaraldehyde (GA). Brains were then removed and postfixed overnight in the same fixative. Two hundred micrometer coronal sections were cut with a vibratome (Leica), postfixed in $2 \%$ osmium tetroxyde for $2 \mathrm{~h}$, dehydrated in crescent concentrations of ethanol, and embedded in Durcupan ACM resin (Sigma-Aldrich). Semithin sections $(1.5 \mu \mathrm{m})$ were obtained with a diamond knife using an ultramicrotome (Ultracut UC-6, Leica) and stained with $1 \%$ toluidine blue. To perform the ultrastructural study, ultrathin sections $(60-70$ $\mathrm{nm}$ ) were cut and stained with lead citrate (Reynold's solution).

For the immunogold procedure, additional six mice (three mutant and three control animals) were perfused with $0.9 \%$ saline, followed by $4 \%$ PFA and $0.5 \%$ GA and then, postfixed in 4\% PFA overnight. One hundred micrometer coronal sections obtained with a vibratome were cryoprotected in $25 \%$ saccharose and freeze-thawed $(3 \times)$ in methylbutane. Sections were washed in $\mathrm{PB}$, blocked in $0.3 \%$ bovine serum albumin-C (BSA) and incubated in primary chicken anti-vimentin antibody (Abcam; 1:500 for $3 \mathrm{~d}$ at $4^{\circ} \mathrm{C}$ ). Sections were washed in PB, blocked in $0.5 \%$ BSA and $0.1 \%$ cold-water fish-skin gelatin (Electron Microscopy Sciences) $1 \mathrm{~h}$ and incubated in colloidal gold-conjugated secondary antibody (1:50; goat anti-chicken IgG gold UltraSmall, Electron Microscopy Sciences) for $24 \mathrm{~h}$ at room temperature. Sections were washed in PB and $2 \%$ sodium acetate. Silver enhancement (Aurion R-gent Silver enhancer kit, Electron Microscopy Sciences) was performed (following manufacturer's directions) and washed again in $2 \%$ sodium acetate. To stabilize silver particles, samples were immersed in $0.05 \%$ gold chloride (Sigma-Aldrich) $10 \mathrm{~min}$ at $4^{\circ} \mathrm{C}$, washed in sodium thiosulfate, then washed in $\mathrm{PB}$, and postfixed in 2\% GA for $30 \mathrm{~min}$. Sections were contrasted with $1 \%$ osmium tetroxyde and $7 \%$ glucose, and processed as 


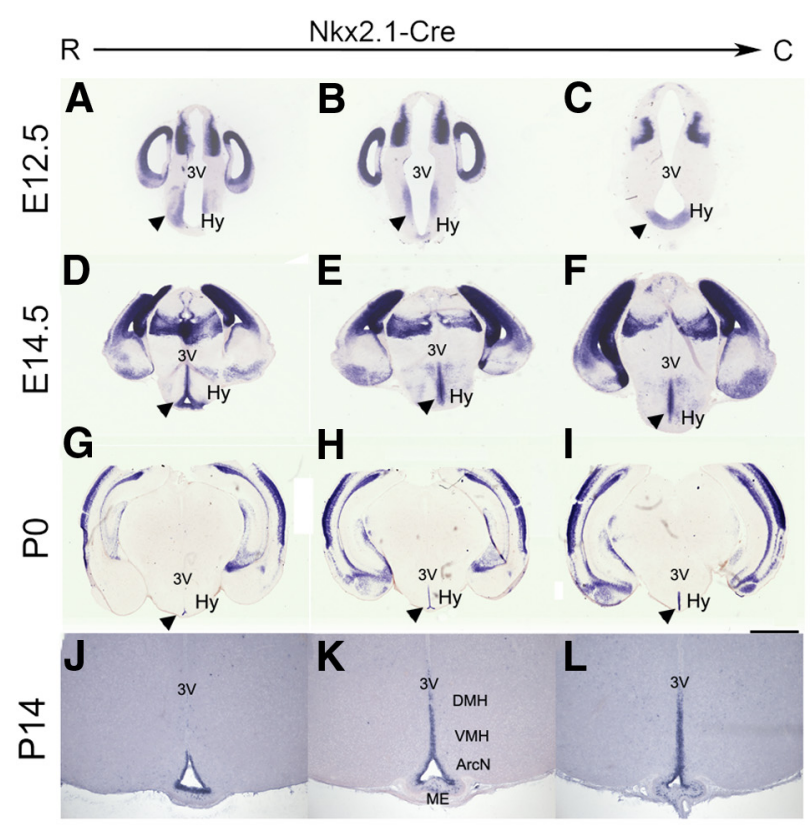

M
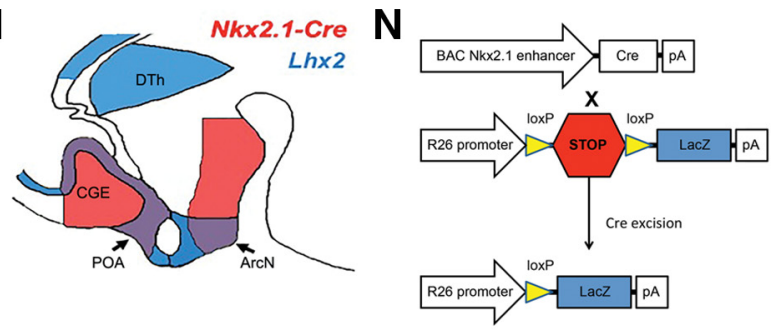

0

Nkx2.1-Cre; R26LacZ
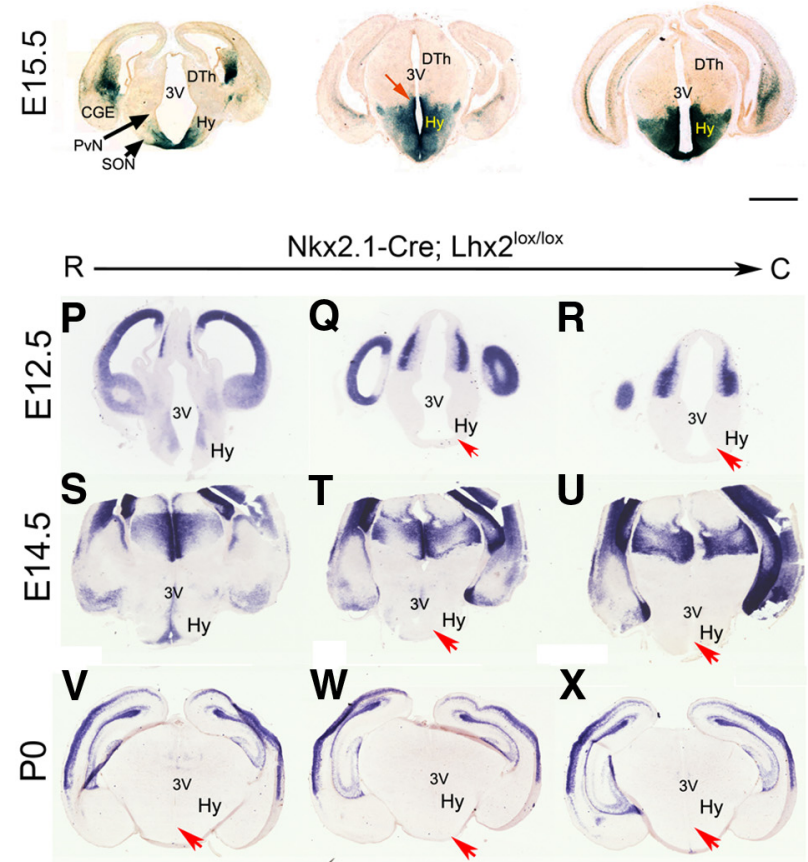

Nkx2.1-Cre; Lhx $2^{10 x / 10 x}$

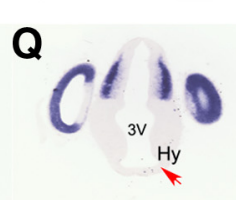

$\mathbf{R}$
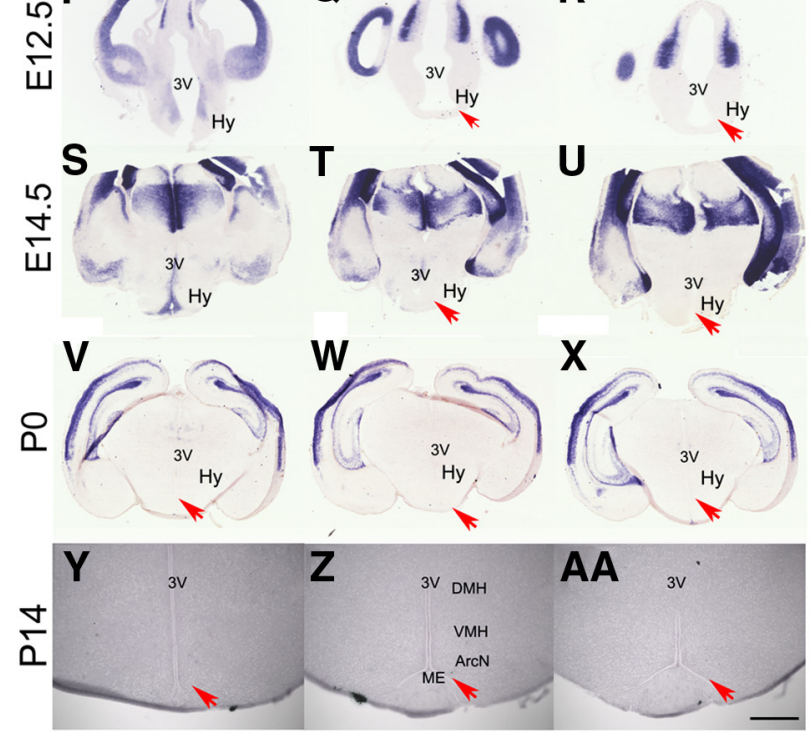

previously described for transmission electron microscopy. Semithin sections were selected at the light microscope based on immunolabeling and re-embedded for ultrathin sectioning at $60-70 \mathrm{~nm}$. For all samples, photomicrographs were obtained under a transmission electron microscope FEI Tecnai G2 Spirit (FEI Europe) using a Morada digital camera (Olympus Soft Image Solutions).

Cell quantification. Average neuronal cell counts across three sections for Npy and five sections for Pomc were calculated for each animal. These averages were then used to calculate means for Npy and Pomc. Npypositive and Pomc-positive cells were those cells that colabeled with probe signal and DAPI. All sections were blinded before counting.

Statistical analyses. Data are expressed as mean \pm SEM. The significance of differences was tested by Student's $t$ test with post hoc Tukey's test ( $>2$ means). The number of experiments $(n)$ performed and $p$ values are reported in the figure legends. Differences were considered significant for $p<0.05$.

\section{Results}

We observe enriched expression of Lhx2 mRNA in embryonic hypothalamic neuroepithelium (Shimogori et al., 2010) and in tanycytes of adult animals (Lee and Blackshaw, 2012; Lee et al., 2012). However, previous studies were performed on sagittal sections and lacked analysis of early postnatal time points (Shimogori et al., 2010). Therefore, we performed an ISH time course analysis from E12.5 to P14 using coronal sections at the level of developing tuberal hypothalamus (Fig. 1). We observed that Lhx2 mRNA is selectively expressed in the ventricular zone of hypothalamic epithelium at E12.5, matching the pattern seen for hypothalamic progenitor-specific mRNAs (Shimogori et al., 2010; Fig. $1 A-C$, black arrowhead). This ventricular expression pattern of $L h x 2$ persisted through E14.5 (Fig. $1 D-F$ ) and P0.5 (Fig. $1 G-$ I). At P14, Lh $\times 2$ mRNA is confined to the cells that line the ventral portion of the third ventricle, which tracks closely with the distribution of hypothalamic tanycytes (Fig. $1 J-L$ ). Based on these findings, we hypothesize that $L h \times 2$ is selectively expressed in hypothalamic progenitor cells and tanycytes.

This expression pattern in embryonic hypothalamic neuroepithelium raises the possibility that $L h \times 2$ might regulate specification of hypothalamic neurons or glia. To address this question, we avoided the embryonic lethality seen in $L h \times 2^{-1-}$ mice (Porter et al., 1997) by generating Nkx2.1-Cre;Lhx $2^{\text {lox/lox }}$ mice (Fig. $1 M, N)$. The Nkx2.1-Cre transgene is first expressed at E9.5 in posteroventral hypothalamic neuroepithelium and in the medial and caudal ganglionic eminences, which give rise to telencephalic interneurons (Xu et al., 2008; Carney et al., 2010). Analysis of Nkx2.1-Cre;R26lacZ mice (Soriano, 1999), which expressed $\beta$-galactosidase under the ubiquitous Rosa26 promoter follow-

Figure 1. $\quad N k x 2.1-C r e ; L h x 2^{l o x / l o x}$ mice show selective loss of $L h x 2$ mRNA in posteroventral hypothalamic progenitors. $\boldsymbol{A}-\boldsymbol{L}$, Black arrows indicate $L h \times 2$ mRNA expression in hypothalamic ventricular zone at E12.5 $(\boldsymbol{A}-\boldsymbol{C})$, at E14.5 $(\boldsymbol{D}-\boldsymbol{F})$, at P0.5 $(\boldsymbol{G}-\boldsymbol{I})$, and at P14 in hypothalamic tanycytes $(\boldsymbol{J}-\boldsymbol{L})$. $\boldsymbol{M}$, Domains of both $N k \times 2.1$ (red) and $L h \times 2$ (blue) expression in a sagittal view of E12.5 forebrain are shown with regions of overlap indicated in purple. Expression data obtained from Shimogori et al. (2010). N, Schematic and diagram for Nkx2.1-Cre; Lhx $2^{\text {lox/lox }}$ intersectional loss of function in ventrobasal hypothalamus. 0, Nkx2.1-Cre;R26lacZ mice reveal that the Nkx2.1-Cre transgene is broadly active in developing posteroventral hypothalamus. Red arrow indicates the dorsal extent of Cre activity, in the developing zona incerta. $\mathbf{P}-\mathbf{A} \boldsymbol{A}$, Conditional loss of function of ventrobasal hypothalamic $L h \times 2$ in Nkx2.1-Cre; Lhx $2^{\text {lox/lox }}$ mice at E12.5 $(\boldsymbol{P}-\boldsymbol{R})$, E14.5 $(\boldsymbol{S}-\boldsymbol{U})$, and P0.5 $(\boldsymbol{V}-\boldsymbol{X})$, and in P14 tanycytes $(\boldsymbol{Y}-\boldsymbol{A A})$. Red arrows in $\boldsymbol{Y}$ and $\boldsymbol{Z}$ indicate selective loss of $L h \times 2$ mRNA from the ventricular zone of ventrobasal hypothalamus. Scale bars: $\boldsymbol{A}-\mathbf{I}, \mathbf{0}-\boldsymbol{X}, 500 \mu \mathrm{m} ; \boldsymbol{J}-\boldsymbol{L}, \boldsymbol{Y}-\mathbf{A A}, 200 \mu \mathrm{m}$. ArcN, Arcuate nucleus; CGE, caudal ganglionic eminence; DMH, dorsomedial hypothalamus; DTh, dorsal thalamus; Hy, hypothalamus; POA, preoptic area; PvN, paraventricular nucleus; SON, supraoptic nucleus; VMH, ventromedial hypothalamus; 3V, third cerebral ventricle. 

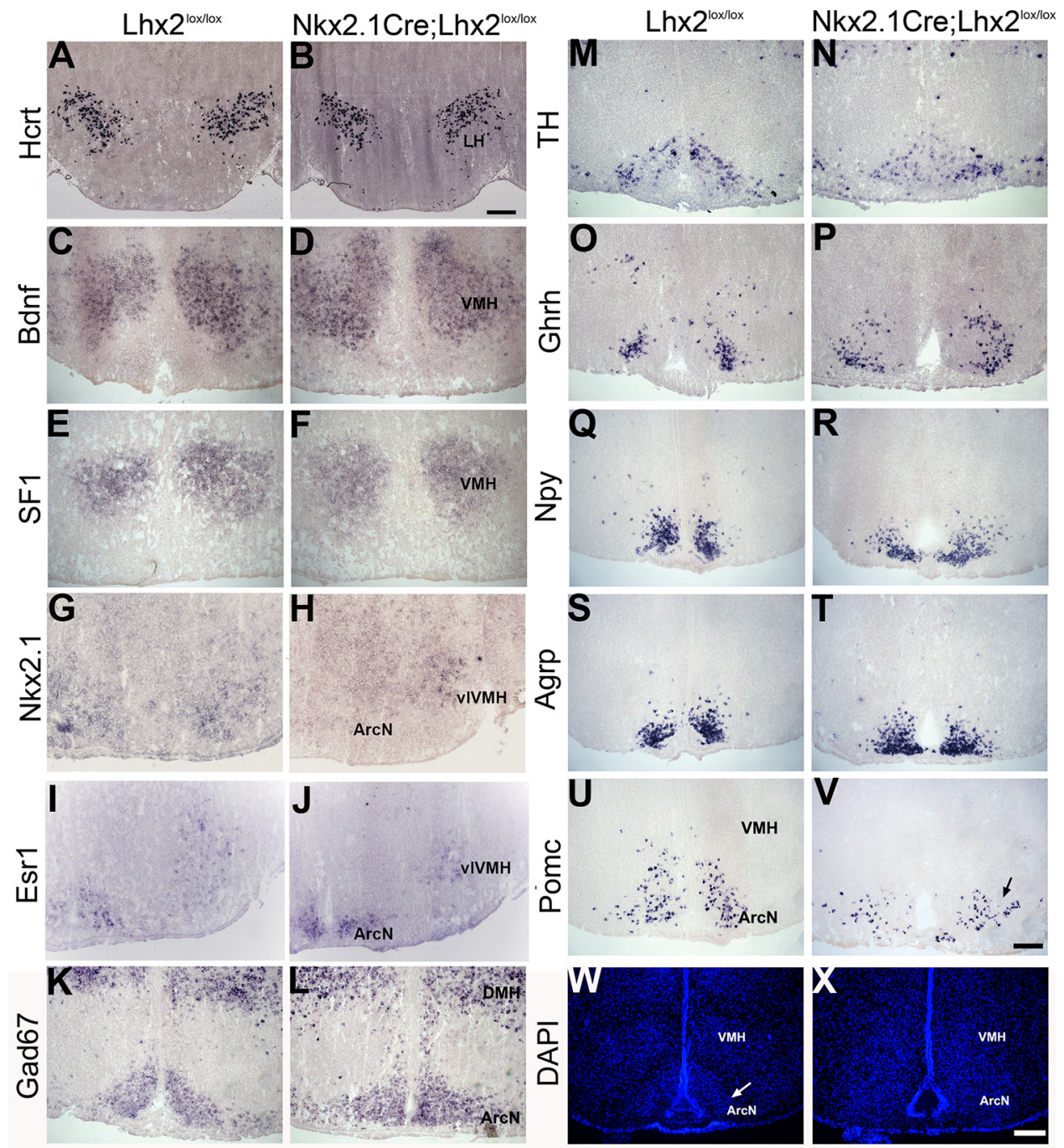

Figure 2. No defects were observed in hypothalamic regional identity or neuronal subtype specification in Nkx2.1-Cre;Lhx2 $2^{\text {lox/lox }}$ mutants. In situ hybridization of cell type-specific markers in arcuate nucleus (ArCN), ventromedial hypothalamic nucleus (VMH), and the lateral hypothalamus (LH). Nkx2.1-Cre; Lhx $2^{\text {lox/lox }}$ mutants and $L h \times 2^{\text {lox/lox }} \operatorname{controls}$ at P14.A-V, LH (A-B), VMH (C-J), and $\operatorname{ArcN}(\boldsymbol{K}-\boldsymbol{V})$ markers are still expressed at normal levels in Nkx2.1-Cre; Lhx $2^{\text {lox/lox }}$ mutants, although cell organization within the ArcN is partially disrupted $(\boldsymbol{U}, \boldsymbol{V}$, black arrow). $\boldsymbol{W}, \boldsymbol{X}, \mathrm{DAPI}$ nuclear stain of the mediotuberal hypothalamus (quantification of mRNA-positive neurons/brain hemisection expressed as mean \pm SEM: Npy: Lhx2 WT, 187.8 $\pm 15.1 ;$ Lhx2 cK0, 200.4 $\pm 14.7, p=0.57, N=$ 5; Pomc: Lhx2 WT, $235.8 \pm 13.2 ;$ Lhx2 cK0, 217.2 $\pm 20.7, p=0.47, N=5)$. Scale bars: $A, B, 500 \mu \mathrm{m} ; \boldsymbol{C}-\boldsymbol{X}, 200 \mu \mathrm{m}$. ArcN, Arcuate nucleus; DMH, dorsomedial hypothalamic nucleus; LH, lateral hypothalamus; vIVMH, ventrolateral ventromedial hypothalamus.

ing Cre-dependent excision of a transcriptional stop cassette in Nkx2.1-expressing cells, revealed that cells of the tuberal hypothalamus were extensively $\beta$-galactosidase positive by E15.5, but the driver was not active in anterior hypothalamic structures, such as the paraventricular and supraoptic nuclei (Fig. 1O). Based on this fate mapping, we used this intersectional genetic strategy to selectively eliminate $L h x 2$ expression in developing tuberal hypothalamus. In $N k x 2.1-C r e ; L h \times 2^{l o x / l o x}$ mice, we observed that loss of Lhx2 mRNA expression was already detectable in tuberal hypothalamic progenitors at E12.5, although expression in rostral hypothalamic and sensory thalamic progenitors remained unaffected (Fig. $1 P-R$ ). By E14.5, Lhx2 mRNA was absent from tuberal hypothalamic progenitors, and remained undetectable thereafter (Fig. 1S-AA).

Nkx2.1-Cre;Lhx $2^{\text {lox/lox }}$ mice were viable and appeared healthy at birth; however, given extensive expression of $L h \times 2$ in hypothalamic progenitors and the importance of $L h \times 2$ in development of neurons in other CNS regions, we first hypothesized that there would be defects in neuronal specification in the Lhx2-deficient region. We examined expression of markers of tuberal and lateral hypothalamic neuronal subtypes at P14. Surprisingly, given the importance of $L h \times 2$ in development of neurons in other CNS regions, we did not observe any changes in the lateral hypothalamic marker Hcrt (Fig. 2A,B); the number of cells expressing the ventromedial hypothalamic nucleus markers $B d n f, S F-1, N k \times 2.1$, and Esr 1 (Fig. 2C-J); or the arcuate nucleus markers Gad67, TH, Cart, Ghrh, Npy, Agrp, and Pomc (Fig. 2K-V). Although no defects were observed in either regional identity or neuronal specification, the organization of the ventral tuberal hypothalamus was abnormal. We observe that the separation of the ventromedial hypothalmus and arcuate nucleus was poorly defined in Nkx2.1-Cre;Lhx $2^{\text {lox } / l o x}$ mice (Fig. $2 W, X$ ), and that the arcuate nucleus was compressed along the dorsoventral axis and extended laterally (Fig. $2 \mathrm{~V}$, black arrow).

We and others previously show that Rax mRNA is selectively expressed starting at E14.5 in the region of hypothalamic neuroepithelium that gives rise to tanycytes (Shimogori et al., 2010; Lu et al., 2013), and that Rax regulates tanycyte development (Miranda- 


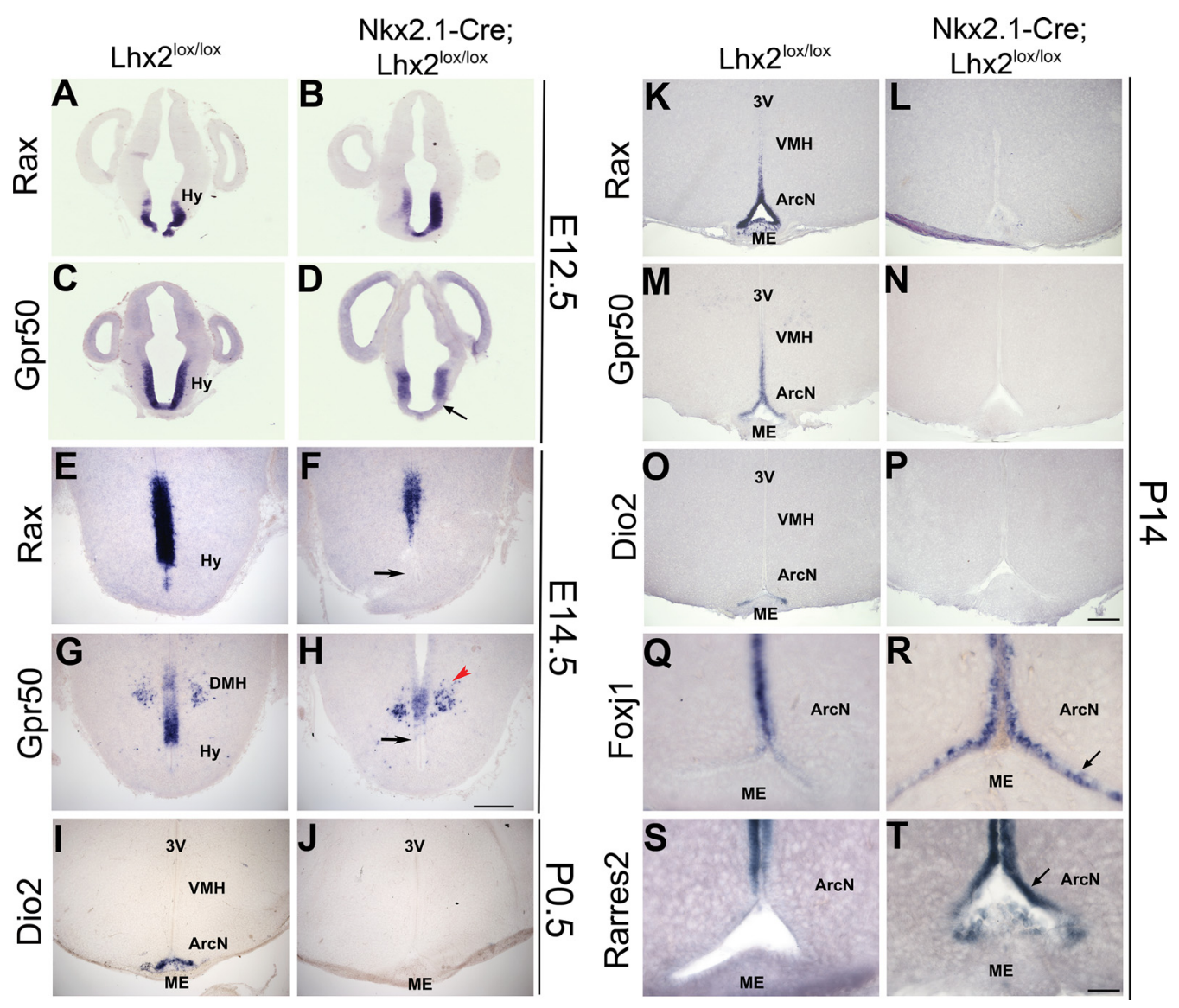

Figure 3. Nkx2.1-Cre; Lhx $2^{\text {lox/lox }}$ mice show selective loss of selective markers of hypothalamic tanycytes and ventral expansion of ependymal cell markers. $A-D, R a x$ mRNA expression is identical in $L h \times 2^{\text {lox/lox }}$ and $N k x 2.1$-Cre; Lhx $2^{\text {lox/lox }}$ mice at E12.5 $(\boldsymbol{A}, \boldsymbol{B})$, although a modest reduction in Gpr50 expression is observed in ventral hypothalamic progenitors at this time point $(\boldsymbol{C}, \boldsymbol{D})$. $\boldsymbol{E}$ - $\boldsymbol{H}$, The black arrow indicates the region in which reduction of Grp50 mRNA is lost from hypothalamic ventricular cells beginning at E14.5 in Nkx2.1-Cre; Lhx $2^{\text {lox/lox }}$ mice. The black arrow indicates loss of Rax expression, while the red arrow indicates Gpr50 expression in developing neurons of the dorsomedial hypothalamus that is not affected in the mutant. I, J, Dio2, a later-onset marker of $\beta 2$ tanycytes of the median eminence, is absent from Nkx2.1-Cre; Lhx2 ${ }^{\text {lox/lox }}$ mice at P0.5. $\boldsymbol{K}$-P, Juvenile (P14) Nkx2.1-Cre; Lhx2 ${ }^{\text {lox/lox }}$ mice show selective loss of tanycyte markers Rax, Gpr50, and Dio2.Q Q-T, Ventral expansion of Foxj 1 and Rarres2 into the $\beta$ tanycytic zone is also observed (black arrow). Scale bars: $\boldsymbol{A}-\boldsymbol{J}, 500 \mu \mathrm{m} ; \boldsymbol{K}-\boldsymbol{P}, 200 \mu \mathrm{m} ; \mathbf{Q}-\boldsymbol{T}, 50 \mu \mathrm{m}$. ArcN, Arcuate nucleus; DMH, dorsomedial hypothalamic nucleus; Hy, hypothalamus; $\mathrm{ME}$, median eminence; VMH, ventromedial hypothalamic nucleus; $3 \mathrm{~V}$, third cerebral ventricle.
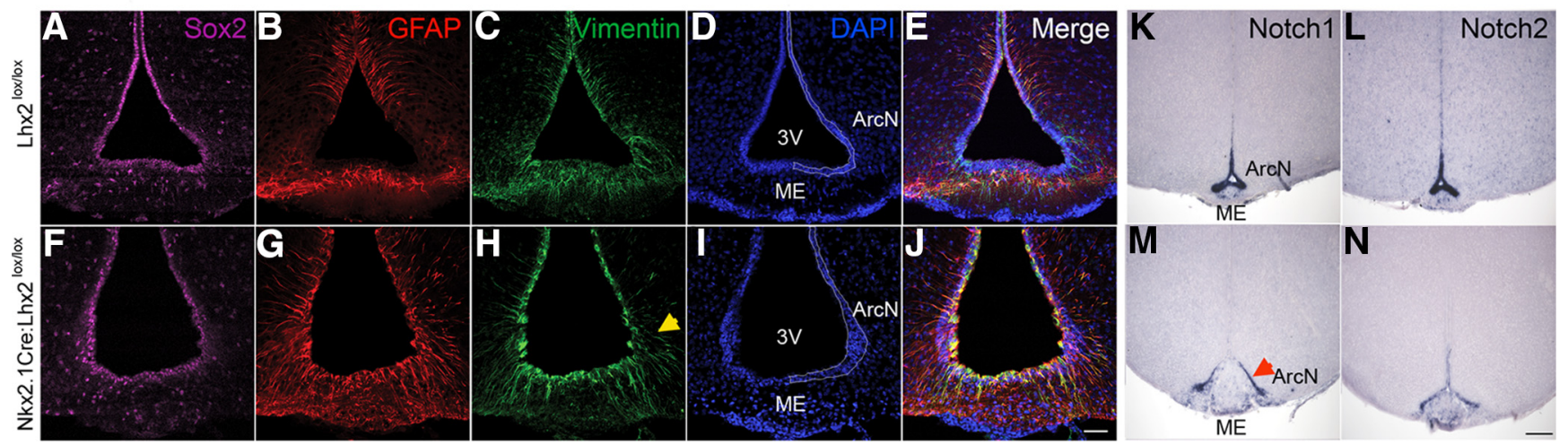

Figure 4. Altered expression of radial glial markers and Notch pathway genes in Nkx2.1-Cre; Lhx2 ${ }^{\text {loxlox }}$ mice. A-J, Immunolabeling for Sox2 (purple), GFAP (red), vimentin (green), and DAPI nuclear stain (blue) in the

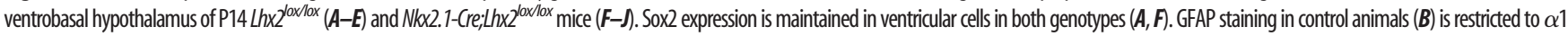
tanycytes and the subependymal layer of the median eminence. Loss of function of $L$ hx2 causes widespread GFAP expression along the third ventricle tanycytes with abundant basal processes (G). Vimentin is expressed in tanycytes in both genotypes with radial processes visible in mutant mice $(\boldsymbol{C}, \boldsymbol{H})$. However, basal processes show abnormal trajectories in mutant tanycytes $(\boldsymbol{H}$, yellow arrowhead). Nuclear counterstain with DAPl labeling

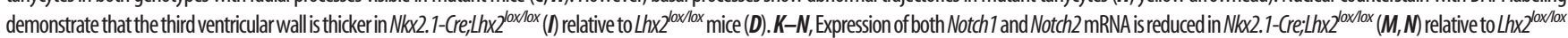
mice $(\boldsymbol{K}, \boldsymbol{L})$. Notch1 expression is selectively retained in the $\alpha 2$ tanycyticzone (red arrow). Scale bars: $\mathbf{A}-J, 50 \mu \mathrm{m} ; \boldsymbol{K}-\mathbf{N}, 100 \mu \mathrm{m}$. ArcN, Arcuate nucleus; ME, median eminence; $3 \mathrm{~V}$, third cerebral ventricle.

Angulo et al., 2014). In addition, expression of Rax is dependent on Lhx2 in the developing retina (Roy et al., 2013). Since the disorganized region we observed in the tuberal hypothalamus borders tanycyte-rich regions of the third ventricle (Fig. 2S,T; Millhouse,
1971; Rodríguez et al., 2005), we hypothesized that Lhx2 regulates tanycyte development by activating expression of Rax.

We next investigated whether expression of tanycyte-specific genes, such as Rax, Gpr50, and Dio2 (Shimogori et al., 2010; Lee 

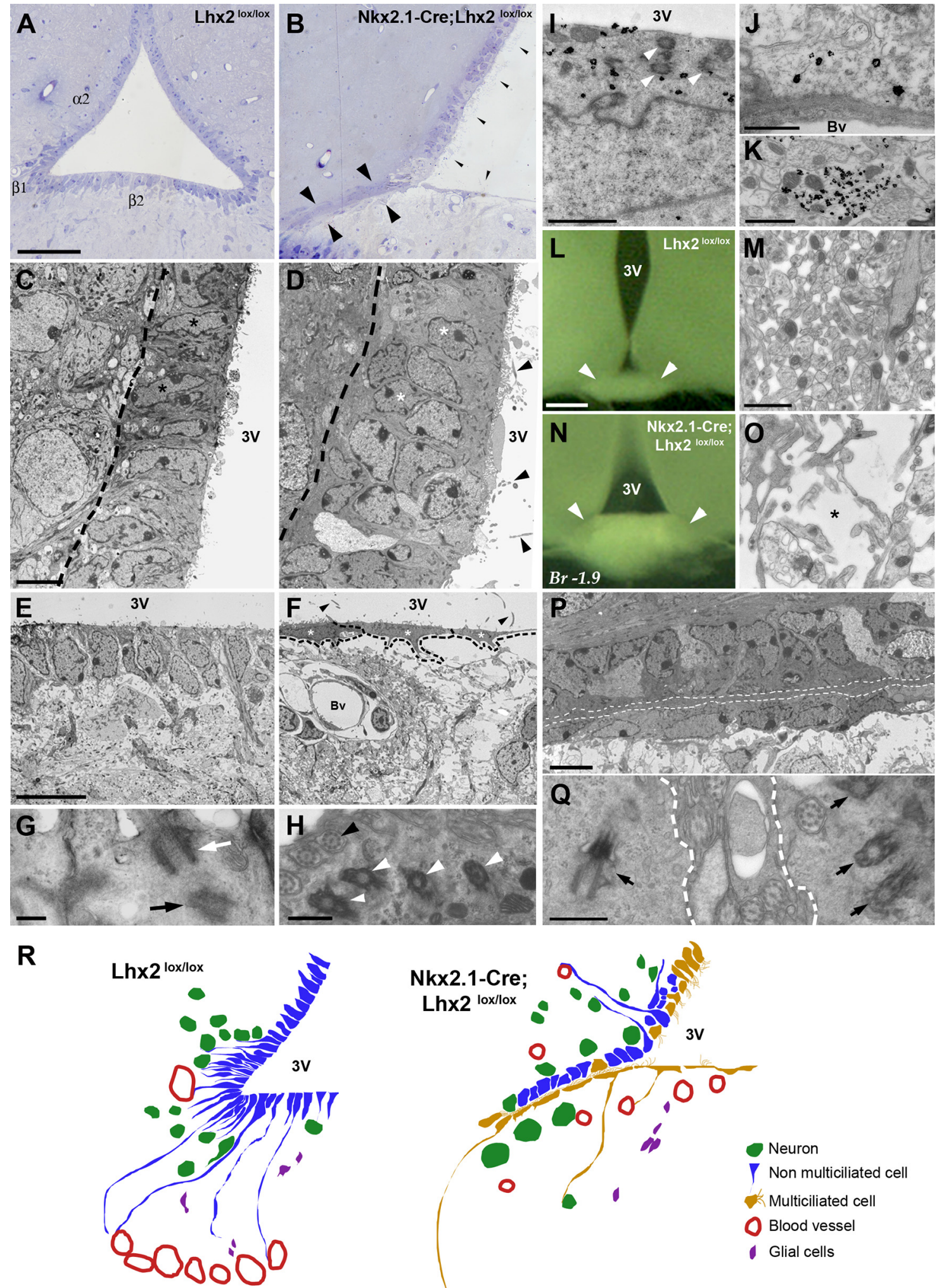

Figure 5. Aberrant cytoarchitecture of the third ventricle in the absence of $L$ hx2. $A, A$ control ventricle semithin section in the region of the median eminence stained with toluidine blue. $\boldsymbol{B}$, In matched sections, mutant mice exhibited a hypertrophic infundibular recess (large black arrowheads). In addition, cilia plumes cover most of the third cerebral ventricle (3V) surface (small black arrowheads). C, The $\alpha 2$ tanycyte region in control mice is a monolayer (dashed line) composed of elongated nonmulticiliated tanycytes. Conversely, Lhx 2 mutants show a stratified ventricle wall (dashed line) composed of both multiciliated and nonmulticiliated cells (black arrowheads). $\boldsymbol{E}, \boldsymbol{F}$, The $\beta 2$ region in control animals is consistently composed of uniciliated tanycytes (D), while flattened multiciliated tanycytes (asterisks) form the $\beta 2$ region in mutant mice (F). Black arrowheads correspond to cilia. G, High-magnification picture of a uniciliated tanycyte in control $\beta 2$ region, with a basal body in the base of its cilium (white arrow) and a perpendicular centriole (black arrow), a characteristic feature of uniciliated cells. High-magnification picture of the mutant ventricle in the region of the median eminence showing a multiciliated cell with basal bodies corresponding to $>1$ cilia (white arrowheads). $\boldsymbol{H}$, Structures with the nine-plus-two morphology characteristic of motile cilia are also observed (black arrowhead). II Immunogold staining against vimentin showing vimentin-positive multiciliated tanycytes in Nkx2.1-Cre; Lhx2 ${ }^{\text {lox/lox }}$ mice, represented by basal bodies (white arrowheads). $\boldsymbol{J}, \boldsymbol{K}$, These aberrant tanycytes contact blood vessels through their vimentin-positive foot processes $(\boldsymbol{J})$ and axons $(\boldsymbol{K})$, (Figure legend continues.) 
and Blackshaw, 2012; Lee et al., 2012), was disrupted in Nkx2.1Cre; Lh $x 2^{\text {lox/lox }}$ mice. We observed that expression of Rax does not differ from controls at E12.5 (Fig. $3 \mathrm{~A}, \mathrm{~B}$ ), although Gpr50 mRNA showed a modest reduction in expression by E12.5 (Fig. 3D, black arrow). Both Rax and Gpr50 showed substantially reduced expression in tuberal hypothalamic progenitors of mutant mice beginning at E14.5 (Fig. $3 F, H$, black arrow), although expression of Gpr50 in immature neurons within the dorsomedial hypothalamic nucleus was unaffected (Shimogori et al., 2010; Fig. $3 H$, red arrowhead). Expression of Dio2, which was first detectable in $\beta 2$ tanycytes of wild-type mice at P0.5, was likewise not detected in tanycytes of Nkx2.1-Cre;Lhx $2^{\text {lox/lox }}$ mice (Fig. 3J). Rax, Gpr50, and Dio2 mRNA were all undetectable in tanycytes of P14 mutant mice (Fig. $3 K-P$ ). At this time point, we also observed ventrally expanded expression of the transcription factor Foxj1, a master transcriptional regulator of multiciliated ependymal cell-specific genes (Fig. 3Q,R; Yu et al., 2008; Choksi et al., 2014). Similarly, we noted a ventral expansion of the ependymal cell marker Rarres2, which was also observed to a less severe extent in Rax haploinsufficient mice (Fig. 3S,T; Miranda-Angulo et al., 2014).

To determine whether tanycytes were absent or had undergone a cell fate change in the hypothalamic ventricular zone of Nkx2.1-Cre; Lh $x 2^{\text {lox/lox }}$ mice, we performed immunohistochemistry at P14 for proteins expressed in both radial glia and tanycytes (Fig. 4). We observed by immunohistochemical staining that cells lining the ventrobasal third ventricle continued to express radial glial markers, such as Sox 2 and vimentin, and that at least a subset of cells retained radial morphology (Fig. $4 A, F, C, H$ ). However, mutant animals demonstrated a myriad of abnormalities. For instance, while $\beta$ tanycytes of wild-type mice did not show GFAP immunoreactivity (Rodríguez et al., 2005; Fig. 4B), an expansion of GFAP immunoreactivity to radial cells in the arcuate and median eminence was observed in mutant animals (Fig. 4G). In addition, the basal processes of $\beta 1$ tanycytes, which normally terminate at the pial surface and regulate blood-hypothalamic barrier function (Mullier et al., 2010), displayed abnormal trajectories (Fig. 4H, yellow arrowhead). Finally, ventricular cells in mutant animals expressed Notch1 and Notch 2 mRNA at lower levels than control mice (Fig. $4 K-N$; Lee et al., 2012).

Ultrastructural analysis at P14 revealed that cells that line the ventral portion of the third ventricle in Nkx2.1-Cre;Lh $x 2^{\text {lox/lox }}$ mice exhibited characteristics of both tanycytes and cuboidal ependymal cells. In the mutant third ventricle wall, it was difficult to delineate the different hypothalamic regions observed in control animals due to the median eminence and corresponding compression of the infindibular recess (Fig. $5 A, B$ ). In contrast to wild-type mice, in which the nuclear morphology of $\alpha$ tanycytes was elongated (Fig. 5C, black asterisk), cells in the $\alpha$ tanycyte zone

\section{$\leftarrow$}

(Figure legend continued.) as seen in control animals. $\boldsymbol{L}, \boldsymbol{N}$, Relative to control mice $(\boldsymbol{L})$, mutant animals display a hyperplastic median eminence ( $\boldsymbol{N}$, white arrowheads). $\boldsymbol{M}$, At the ultrastructural level, the median eminence of control mice has few intracellular spaces. $\mathbf{0}$, In contrast, mutant median eminence appears as a disorganized hypocellular layer, with multiple and large intercellular spaces (black asterisk). $\boldsymbol{P}$, Hyperplasia of the median eminence into the ventricle leads to compression of the infundibular recess, so that $\alpha 2$ tanycytes directly contact $\beta 2$ tanycytes, thereby reducing the ventricle lumen to a virtual cavity (dashed white line). $\mathbf{Q}$, High-magnification picture of this region shows a uniciliated cell from the $\alpha 2$ region opposite a multiciliated cell from $\beta 2$ region. Black arrowheads indicate cilia. $\boldsymbol{R}$, Schematic drawing of ventricle in coronal section in the region of the median eminence showing the distribution of cell types in the ventricular zone of the $3 \mathrm{~V}$. Scale bars: $\boldsymbol{A}, \boldsymbol{B}, 50 \mu \mathrm{m} ; \boldsymbol{C}, \boldsymbol{D}, 5 \mu \mathrm{m} ; \boldsymbol{E}, \boldsymbol{F}, 10 \mu \mathrm{m} ; \boldsymbol{G}$, $200 \mathrm{~nm} ; \boldsymbol{H}, 500 \mathrm{~nm} ; \boldsymbol{I}, 1 \mu \mathrm{m} ; \boldsymbol{J}, 500 \mathrm{~nm} ; \boldsymbol{K}, 1 \mu \mathrm{m} ; \boldsymbol{L}, \boldsymbol{N}, 250 \mu \mathrm{m} ; \boldsymbol{M}, \mathbf{0}, 1 \mu \mathrm{m} ; \boldsymbol{P}, 5 \mu \mathrm{m} ; \boldsymbol{Q}, 500$ $\mathrm{nm}$. Bv, Blood vessel.
Table 1. List of Cre lines used for this study

\begin{tabular}{|c|c|c|c|}
\hline Cre line & Where expressed & $\begin{array}{l}\text { When } \\
\text { active }\end{array}$ & Reference \\
\hline Nkx2.1-Cre & Posterioventral hypothalamus & E9.5 & Xu et al., 2008 \\
\hline Foxd1-Cre & All hypothalamus and prethalamus & $\sim$ E9.5 & $\begin{array}{l}\text { Humphreys et al., 2008; this } \\
\text { study }\end{array}$ \\
\hline Rax-CreER ${ }^{\mathrm{T} 2}$ & All tanycytes & $\mathrm{P} 1.5^{*}$ & Pak et al., 2014 \\
\hline Glast-CreER $^{\mathrm{T} 2}$ & Alpha tanycytes & $\mathrm{P} 4.5^{*}$ & $\begin{array}{l}\text { de Melo et al., 2012; Robins } \\
\text { et al., } 2013\end{array}$ \\
\hline
\end{tabular}

*Age at which tamoxifen is first administered.

in mutant animals showed cuboid morphology (Fig. 5D, white asterisk) along with a clear thickening of the ventricle wall (Fig. $5 D)$. This thickening ventricular wall stands in contrast to the phenotype observed in Rax haploinsufficient mice, where a thinning of ventricular wall is observed (Miranda-Angulo et al., 2014). Notably, multiciliated cells were interspersed in this region that contains only uniciliated cells in wild-type animals (Fig. $5 D$, black arrowheads). $\beta$ Tanycytes in the median eminence demonstrated even more pronounced morphological changes. While wild-type animals exhibited elongated nuclear morphology similar to that of $\alpha$ tanycytes (Fig. 5E), cells in this region in mutant mice displayed flattened and horizontally distended cell bodies and nuclei (Fig. 5F, white asterisk). These cells also revealed multiple cilia, never detected in this region in control mice (Fig. 5F, black arrowheads), as demonstrated by the observation of multiple basal bodies with characteristic features. Furthermore, these cilia exhibited a nine-plus-two morphology characteristic of motile cilia, in sharp contrast to the nonmotile primary cilia of tanycytes (Fig. 5G,H).

Despite these morphological differences, mutant cells retained a number of tanycyte-like features, including an enlarged Golgi apparatus, radial glial-like morphology, and vimentin expression in foot processes that made direct contacts with blood vessels and neurons (Fig. 5I-K). The median eminence displayed cytoarchitectural changes that imply considerable disorganization characterized by increased volume and large intercellular spaces (Fig. $5 \mathrm{~L}, \mathrm{O}$ ). This increase in volume may be responsible for the hypertrophy of the infundibular recess seen in mutant mice, and the obliterated ventricle lumen in the region where multiciliated $\beta$ tanycytes and uniciliated $\alpha$ tanycytes were appositioned (Fig. 5P, Q). These observations are summarized in Figure $5 R$. Thus, these dramatic changes in ultrastructure imply that loss of $L h \times 2$ function selectively compromised terminal differentiation of hypothalamic tanycytes. Lhx2 prevented radial cells from adopting a number of morphological and molecular characteristics of cuboid ependymal cells, but was not required for their survival or for maintenance of their radial morphology.

Since robust $L h \times 2$ expression is maintained in differentiated tanycytes (Fig. 1J-L; Lee et al., 2012), we next sought to determine whether Lhx2 was required to maintain tanycyte identity in the postnatal period. We assessed this using two different conditional Cre lines prominently expressed in adult tanycytes. The first of these is the RaxCreER ${ }^{T 2}$ line (Table 1), in which a tamoxifen-inducible Cre is expressed from the endogenous first coding exon of the Rax gene (Pak et al., 2014). Paralleling the endogenous expression of Rax, this Cre was selectively active in developing tanycytes in neonatal mice (Fig. 6A, C$H)$. RaxCreER $R^{T 2} ; \operatorname{Lh} \times 2^{\text {lox/lox }}$ mice and littermate controls were intraperitoneally administered 4-OHT from P1 to P3. At P14, we found that these animals showed a substantial loss of Lhx2 mRNA expression in all classes of tanycytes, although some 
A

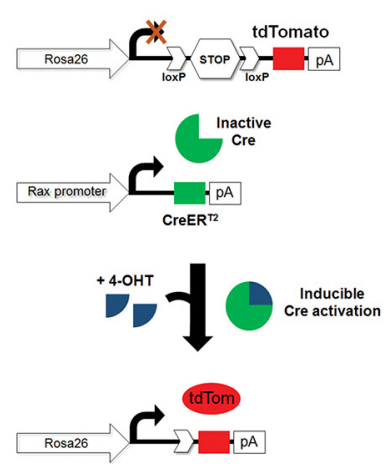

B

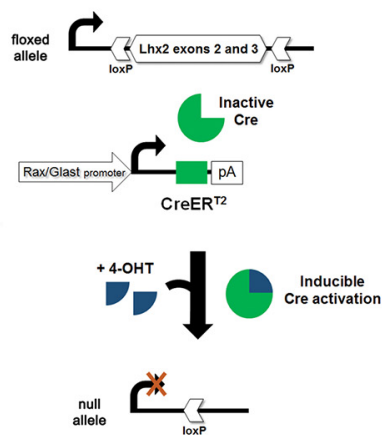

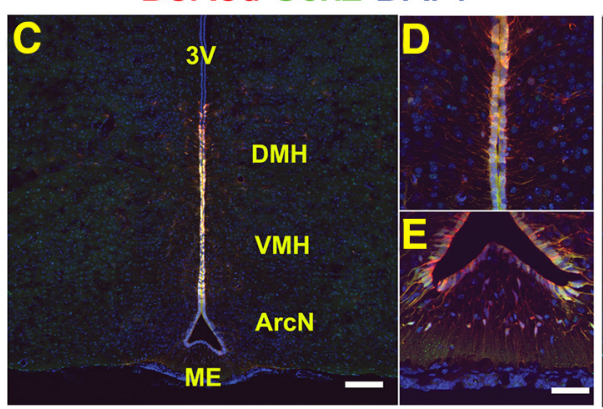
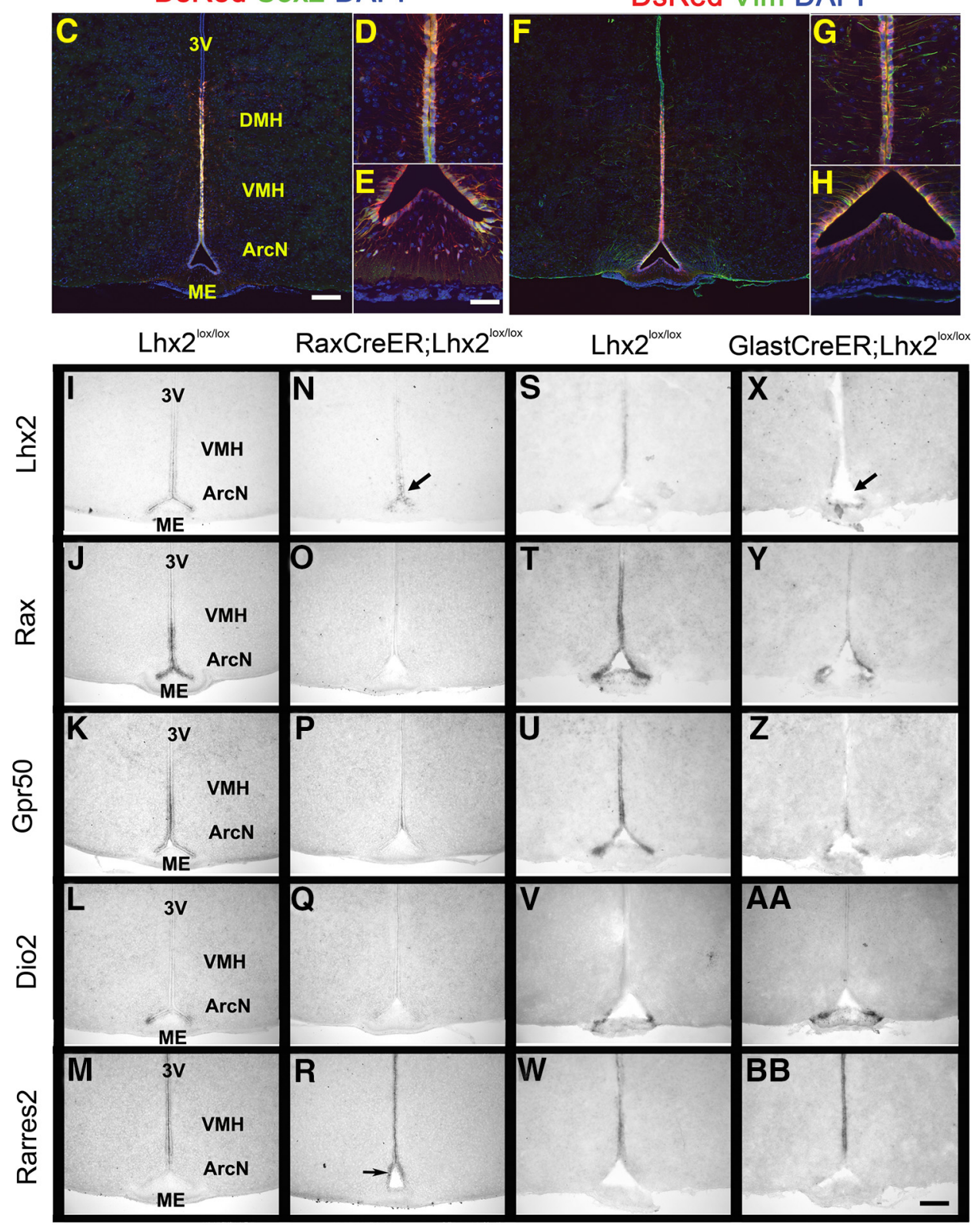

Figure 6. Lhx2 is necessary for postnatal development and maintenance of tanycyte identity. $A, B$, Schematic illustrating CreER-dependent activation of tdTomato expression and Lhx2 excision. C-N, Immunostaining for DsRed, Sox2, and vimentin shows selective activation of RaxCreER in hypothalamic tanycytes. Neonatal (Rax-CreER ${ }^{T 2}$ i $\left.L h \times 2^{\text {lox/lox}}\right)$ deletion of $L h \times 2$ leads to partial loss of $L h x 2$ expression $(\boldsymbol{I}, \boldsymbol{N})$. A limited level of mosaic expression is detected in the $\alpha$ tanycytic zone in mutant mice (N, black arrow). $\mathbf{O}-\mathbf{Q}$, Loss of $L h \times 2$ disrupts tanycytic expression of Rax (0), Gpr50 (P), and Dio2 (Q) $) \cdot \boldsymbol{R}$, Ventral expansion of Rarres2 expression into the $\alpha 2$ tanycytic zone is also observed resulting from Rax haploinsufficiency (black arrow).

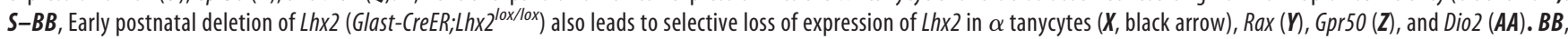
However, Rarres2 mRNA expression is not expanded ventrally. Scale bars: $\boldsymbol{C}, \boldsymbol{F}, \boldsymbol{I}-\boldsymbol{B} \boldsymbol{B}, 200 \mu \mathrm{m} ; \boldsymbol{D}, \boldsymbol{E}, \boldsymbol{G}, \boldsymbol{H}, 70 \mu \mathrm{m}$.

Lhx2-positive cells were still detected in hypothalamic neuroepithelium (Fig. 6I,J). We observed a complete loss of expression of the tanycyte markers Rax, Gpr50, and Dio2 (Fig. 6OQ). We also detected an extension of Rarres2 expression, an ependymal cell marker, into the $\alpha 2$ tanycyte region of the arcuate nucleus (Fig. $6 M, R$ ).

As a second parallel approach to ascertain whether Lhx2 was required to maintain tanycyte identity in the postnatal period, we generated a slightly later loss of Lhx2 function in tanycytes using the Glast-CreER transgene (Table 1), which is selectively expressed in $\alpha$ tanycytes (Robins et al., 2013). Following 4-OHT injections delivered from P4 to P10 to Glast-
CreER;Lhx $2^{\text {lox/lox }}$ mice, we examined Lhx2 and tanycyte marker expression at P14. We observed that $L h x 2$ mRNA expression was greatly reduced in $\alpha$ but not $\beta$ tanycytes (Fig. $6 S, X)$, as would be expected from the use of this transgenic driver. Expression of tanycytic markers Rax and Gpr50 were also selectively lost in $\alpha$ but not $\beta$ tanycytes (Fig. 6T, $Y, U, Z$ ), while Dio2 expression, which is restricted to $\beta$ tanycytes, was unaffected (Fig. $6 \mathrm{~V}, A A$ ). In contrast to the embryonic loss of function of Lhx2 seen in Nkx2.1-Cre; Lhx $2^{\text {lox/lox }}$ and RaxCre$E R^{T 2} ;$ Lh $x 2^{\text {lox/lox }}$ mice given 4 -OHT at earlier postnatal time points, we did not observe a ventral expansion of the ependymal marker Rarres2 in Glast-CreER;Lhx $2^{\text {lox/lox }}$ mice (Fig. 
A

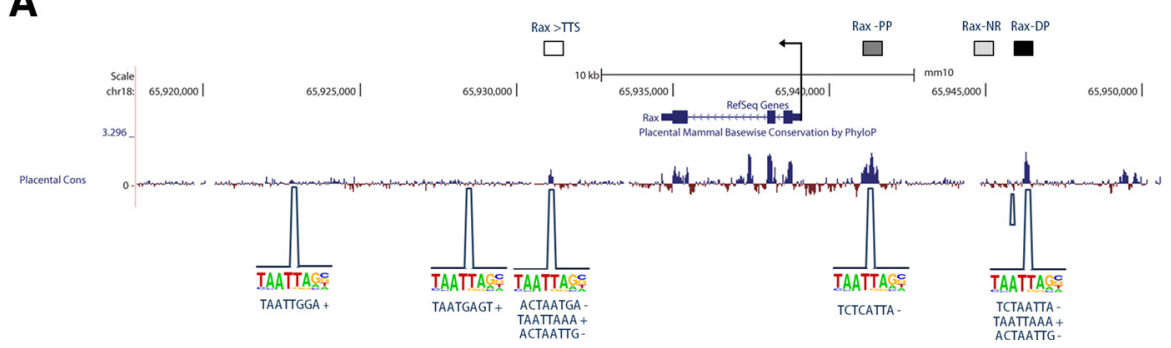

B

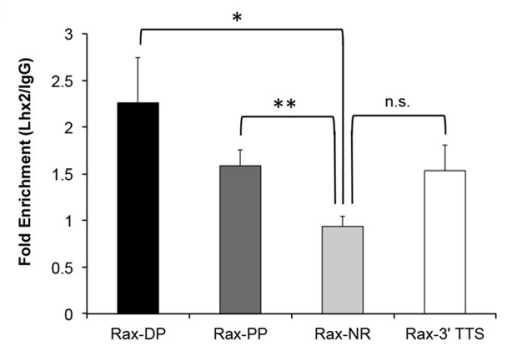

Figure 7. Lhx2 directly regulates Rax expression in postnatal hypothalamus. A, Candidate Lhx2 binding sites located within $15 \mathrm{~kb}$ of the Rax locus, obtained from the University of California Santa Cruz Genome Browser. Evolutionary sequence conservation is indicated in blue. The consensus Lhx2 binding site, as determined by protein-binding microarray analysis, is indicated for each region where a candidate binding site is found. The sequence of these sites is shown below. The three test amplicons used in this study are indicated as Rax $>$ TTS ( $3^{\prime}$ of transcription termination site), Rax-PP (Rax proximal promoter), and Rax-DP (Rax distal promoter). Rax-NR, Negative control amplicon that lacks a candidate Lhx2 binding site. B, ChIP-qPCR analysis demonstrates that Lhx2 binds to candidate Lhx2 target sites adjacent to the Rax locus in P7 hypothalamus. Signal is shown normalized relative to conspecific lgG controls. n.s., Not significant. $p=0.056 ;{ }^{*} p<0.05 ;{ }^{* *} p<0.01$.
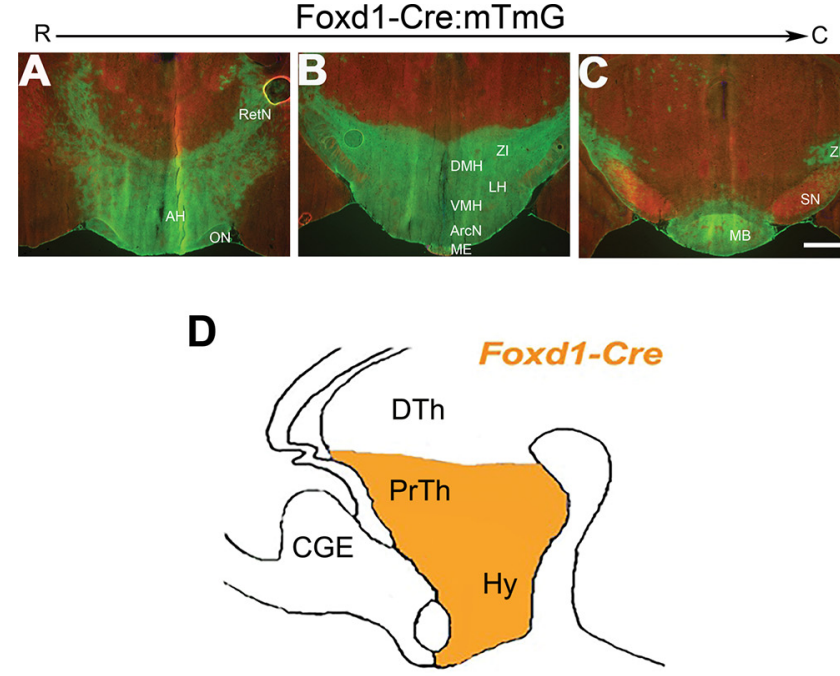

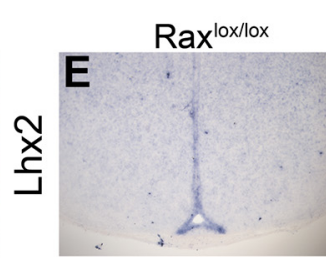

G
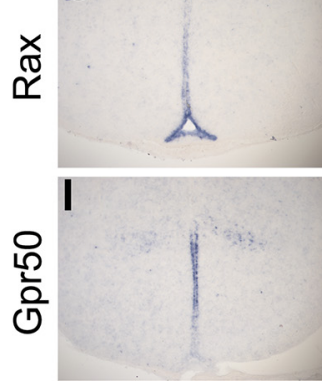

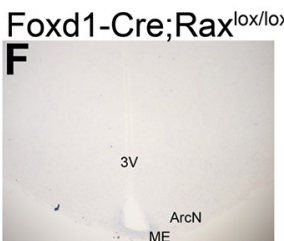

H

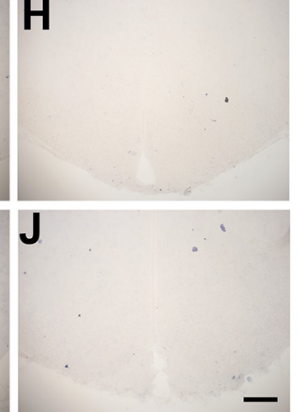

Figure 8. Loss of Rax function leads to loss of both Lhx2 and tanycyte marker expression. Cre-induced GFP reporter expression in Foxd1-Cre;tmRtmG mice shows broad and selective labeling of cells in hypothalamus and prethalamus of adult mice (A-C). D, Schematic representation of Foxd1-Cre activity in the hypothalamus, adapted from Shimogori et al. (2010). $\boldsymbol{E}-\boldsymbol{J}$, Embryonic deletion of Rax

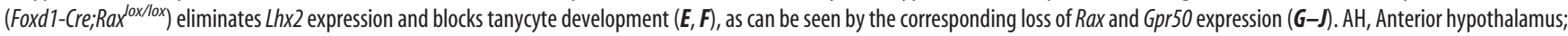
ArcN, arcuate nucleus; CGE, caudal ganglionic eminence; DMH, dorsomedial hypothalamic nucleus; DTh, dorsal thalamus; Hy, hypothalamus; LH, lateral hypothalamus; MB, mamillary body; ME, median eminence; $\mathrm{ON}$, optic nerve; PrTh, prethalamus; RetN, thalamic reticular nucleus; $\mathrm{SN}$, substantia nigra; $\mathrm{VMH}$, ventromedial hypothalamic nucleus; Zl, zona incerta; $3 \mathrm{~V}$, third cerebral ventricle. Scale bars: $A-C, 500 \mu \mathrm{m} ; \boldsymbol{E}-J, 200 \mu \mathrm{m}$.

$6 W, B B)$. These data imply that Lhx 2 is required for maintenance of tanycyte identity following the early postnatal period, but is not required for repression of ependymal cell identity.

Given the similarities between the phenotypes of Lhx2deficient and Rax-haploinsufficient tanycytes (Miranda-Angulo et al., 2014) and the requirement of Lhx 2 to maintain Rax expression in retinal progenitor cells (Roy et al., 2013), we hypothesized that Lhx2 directly activates Rax expression in tanycytes. To address this question, we performed a ChIP-qPCR assay using chromatin from P7 hypothalamus, targeting candidate Lhx2 binding sites in evolutionarily conserved candidate regulatory regions of Rax. We observe that Lhx2 directly bound to two different evolutionarily conserved putative cis-regulatory sequences within 15 $\mathrm{kb}$ of the transcribed Rax locus (Fig. 7A,B), strongly implying that Lhx2 directly activates Rax transcription in hypothalamic tanycytes.

These data suggest that $L h x 2$ controls tanycyte differentiation at least in part by directly maintaining expression of Rax in developing tanycytes. To determine whether developmental loss of function of Rax phenocopied the loss of function of $L h x 2$, we generated hypothalamus-specific Rax mutants and examined the effects on both $L h x 2$ expression and tanycyte development in neonatal mice. We accomplished this using Foxd1-Cre mice (Table 1), in which a Cre recombinase has been nondisruptively knocked into the endogenous Foxd1 locus (Humphreys et al., 2008). Our group and others have previously observed that Foxd1 mRNA is selectively and broadly expressed in early prethalamic and hypothalamic progenitors, but is absent from telencephalic progenitor cells (Hatini et al., 1996; Shimogori et al., 2010). By generating Foxd1-Cre;tmRtmG mice, we observed that Cre-induced GFP expression is observed throughout the hypothalamus and prethalamus, but is absent from other brain regions in the adult (Fig. 8A-D). We then generated Foxd1-Cre;Rax lox/lox mice and characterized the expression of $L h \times 2$ and tanycytespecific markers at P0.5. Rax mRNA is lost from the hypothalamic ventricular zone, along with $L h \times 2$ and the tanycyte marker Gpr50 (Fig. 8E-J). These data demonstrate a mutually interdependent requirement for $L h x 2$ and Rax expression in embryonic hypothalamus, and show that both Lhx2 and Rax are essential for tanycyte specification. 


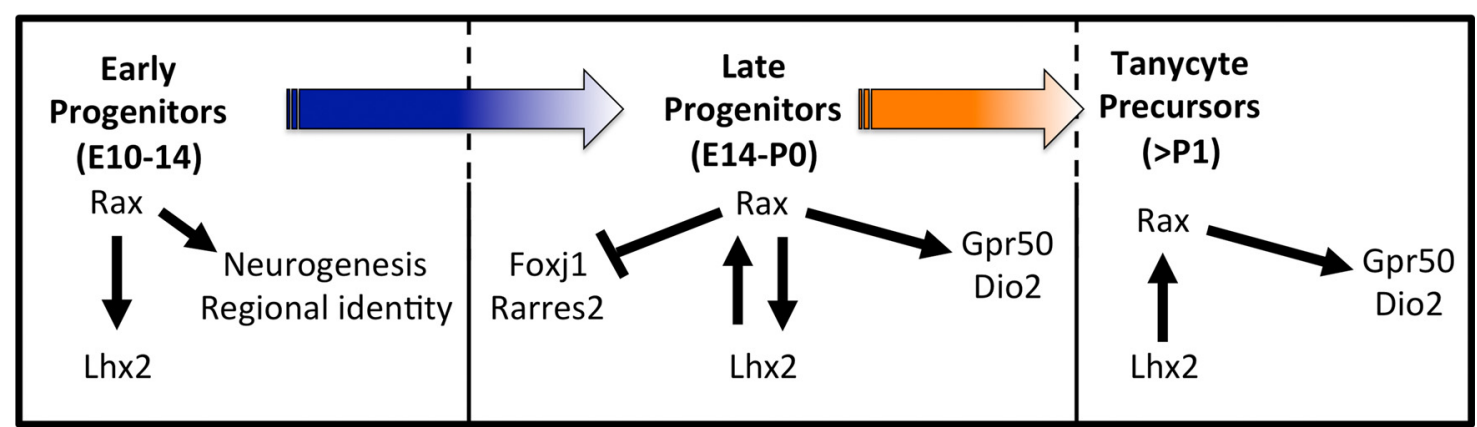

Figure 9. Model for action of Rax and Lhx2 in control of tanycyte development. Rax is required for initial expression of $L h x 2$ in ventrobasal hypothalamic progenitors. Lhx 2 is later directly required to maintain Rax expression in tanycyte progenitors, which then acts to promote tanycyte differentiation while repressing multiciliated ependymal cell identity. Defects in tanycyte development resulting from loss of Lhx2 are partially mediated by defective expression of Rax.

\section{Discussion}

Radial glial cells lining the embryonic ventricular neuroepithelium not only serve as progenitors for many neurons and glial cells soon after birth, but also give rise to adult neural stem cells that continue to produce neurons throughout adult life (Campbell and Götz, 2002; Merkle et al., 2004). In virtually all areas of the adult CNS, however, radial glia are absent, and instead multiciliated cuboid ependymal cells line the cerebral ventricle walls. An exception to this is the ventrobasal hypothalamus and other circumventricular organs, whose ventricular cells are enriched for tanycytes, a specialized radial glial-like cell type. Like adult neural stem cells found in neurogenic niches of the hippocampus and the lateral ventricles, hypothalamic tanycytes also continue to express stem-specific and progenitor-specific genes into adulthood (Lee and Blackshaw, 2012; Lee et al., 2012), and a subset of these tanycytes remain as neural progenitors exhibiting limited neurogenic potential (Lee et al., 2012, 2013, 2014; Haan et al., 2013; Robins et al., 2013). Potential uses of these hypothalamic neural progenitor cells include transplantation for cell replacement (Czupryn et al., 2011) and/or the activation of endogenous cells to promote self-repair (Pierce and $\mathrm{Xu}, 2010$; Lee and Blackshaw, 2014). Furthermore, tanycytes regulate metabolism and body weight through other mechanisms, including through transport of leptin and regulation of the blood-hypothalamus barrier (Langlet et al., 2013; Balland et al., 2014). To understand precisely how tanycytes maintain these characteristics, it is necessary to better understand the transcriptional regulatory networks that control tanycytespecific gene expression.

Transcriptional regulatory networks that are active in adult neural progenitors often mirror those seen in embryonic and early postnatal progenitors in the same brain regions (Ming and Song, 2011; Hsieh, 2012). With this in mind, we examined the transcriptional factors involved in the developmental specification of tanycytes. In this study, we showed that selective loss of Lhx2 in both embryonic and postnatal hypothalamus disrupted terminal differentiation of tanycytes, eliminating expression of tanycyte-specific genes, such as Rax (Miranda-Angulo et al., 2014) and Gpr50 (Shimogori et al., 2010). Lhx2-deficient hypothalamic ventricular cells survived and retained radial morphology, but upregulated expression of GFAP, much like what is observed in Lhx2-deficient retinal Muller glia (de Melo et al., 2012). Loss of $\operatorname{Lh} x 2$ in hypothalamic neuroepithelium led to tanycytes becoming multiciliated, presumably as a result of ectopically expressing Foxj1, a master transcriptional regulator of multiciliated ependymal cell-specific gene expression (Brody et al., 2000; Stubbs et al., 2008; Yu et al., 2008). Upregulation of ependymal cell markers was not seen following postnatal loss of Lhx2 function, however. This implies that Lhx2 is necessary to repress Foxj1 expression during initial stages of tanycyte specification, but is only required to maintain expression of tanycyte-specific genes during postnatal development. Figure 9 summarizes these results.

Genetic analysis and ChIP-qPCR revealed that Lhx2 directly bound to sites in evolutionarily conserved putative cis-regulatory sequences of Rax, and thus strongly suggests direct activation of Rax transcription (Fig. 7). While Rax-haploinsufficient mice exhibit modest abnormalities in tanycyte development and function (Miranda-Angulo et al., 2014), we now show that mice in which Rax expression in hypothalamic progenitors was fully disrupted (Fig. 8) lack any detectable expression of tanycyte-specific marker genes, much like what was observed in Lhx2-deficient animals (Figs. 3, 6).

In sharp contrast to its role in retinal neurogenesis (Gordon et al., 2013; Roy et al., 2013), $L h \times 2$ is not required to maintain Rax expression during the peak period of neurogenesis in ventrotuberal hypothalamus, which lasts from E11 to E14 (Shimada and Nakamura, 1973; Shimogori et al., 2010). Likewise, Nkx2.1-Cre; Lhx $x^{l o x / l o x}$ mice did not show defects in specification of tuberal hypothalamic neurons (Fig. 2), in sharp contrast to Rax-deficient mice (Lu et al., 2013). We thus conclude that $L h x 2$ plays a central but highly selective role in tuberal hypothalamus development: driving the specification and terminal differentiation of hypothalamic tanycytes, by maintaining their expression of Rax. These findings reinforce the tremendous degree of context dependence in Lhx2 function (Monuki et al., 2001; Rhee et al., 2006; Richter et al., 2006; Mangale et al., 2008; Yun et al., 2009; de Melo et al., 2012; Gordon et al., 2013; Roy et al., 2013), and highlights the need for biochemical studies to identify cofactors that mediate these diverse cell-specific and stage-specific developmental actions of $L h x 2$.

This work identifies a key new component of the transcriptional circuitry regulating hypothalamic tanycyte identity, and provides an entry point toward identifying additional regulators of tanycyte proliferation, differentiation, and function. Furthermore, this mechanistic knowledge will improve our understanding of how these specialized cells regulate metabolism and energy balance. As with studies of hypothalamic development more generally (Caqueret et al., 2005; Blackshaw et al., 2010; Pearson and Placzek, 2013), this will potentially provide important insights into the pathogenesis of metabolic and homeostatic disorders in humans. 


\section{References}

Allen NJ, Barres BA (2009) Neuroscience: glia—more than just brain glue. Nature 457:675-677. CrossRef Medline

Balland E, Dam J, Langlet F, Caron E, Steculorum S, Messina A, Rasika S, Falluel-Morel A, Anouar Y, Dehouck B, Trinquet E, Jockers R, Bouret SG, Prévot V (2014) Hypothalamic tanycytes are an ERK-gated conduit for leptin into the brain. Cell Metab 19:293-301. CrossRef Medline

Blackshaw S, Snyder SH (1997) Parapinopsin, a novel catfish opsin localized to the parapineal organ, defines a new gene family. J Neurosci 17:80838092. Medline

Blackshaw S, Scholpp S, Placzek M, Ingraham H, Simerly R, Shimogori T (2010) Molecular pathways controlling development of thalamus and hypothalamus: from neural specification to circuit formation. J Neurosci 30:14925-14930. CrossRef Medline

Bolborea M, Dale N (2013) Hypothalamic tanycytes: potential roles in the control of feeding and energy balance. Trends Neurosci 36:91-100. CrossRef Medline

Brody SL, Yan XH, Wuerffel MK, Song SK, Shapiro SD (2000) Ciliogenesis and left-right axis defects in forkhead factor HFH-4-null mice. Am J Respir Cell Mol Biol 23:45-51. CrossRef Medline

Campbell K, Götz M (2002) Radial glia: multi-purpose cells for vertebrate brain development. Trends Neurosci 25:235-238. CrossRef Medline

Caqueret A, Yang C, Duplan S, Boucher F, Michaud JL (2005) Looking for trouble: a search for developmental defects of the hypothalamus. Horm Res 64:222-230. CrossRef Medline

Carney RS, Mangin JM, Hayes L, Mansfield K, Sousa VH, Fishell G, Machold RP, Ahn S, Gallo V, Corbin JG (2010) Sonic hedgehog expressing and responding cells generate neuronal diversity in the medial amygdala. Neural Dev 5:14. CrossRef Medline

Choksi SP, Lauter G, Swoboda P, Roy S (2014) Switching on cilia: transcriptional networks regulating ciliogenesis. Development 141:1427-1441. CrossRef Medline

Czupryn A, Zhou YD, Chen X, McNay D, Anderson MP, Flier JS, Macklis JD (2011) Transplanted hypothalamic neurons restore leptin signaling and ameliorate obesity in $d b / d b$ mice. Science 334:1133-1137. CrossRef Medline

de Melo J, Miki K, Rattner A, Smallwood P, Zibetti C, Hirokawa K, Monuki ES, Campochiaro PA, Blackshaw S (2012) Injury-independent induction of reactive gliosis in retina by loss of function of the LIM homeodomain transcription factor Lhx2. Proc Natl Acad Sci U S A 109:4657-4662. CrossRef Medline

Gao Y, Tschöp MH, Luquet S (2014) Hypothalamic tanycytes: gatekeepers to metabolic control. Cell Metab 19:173-175. CrossRef Medline

Gordon PJ, Yun S, Clark AM, Monuki ES, Murtaugh LC, Levine EM (2013) Lhx2 balances progenitor maintenance with neurogenic output and promotes competence state progression in the developing retina. J Neurosci 33:12197-12207. CrossRef Medline

Haan N, Goodman T, Najdi-Samiei A, Stratford CM, Rice R, El Agha E, Bellusci S, Hajihosseini MK (2013) Fgf10-expressing tanycytes add new neurons to the appetite/energy-balance regulating centers of the postnatal and adult hypothalamus. J Neurosci 33:6170-6180. CrossRef Medline

Hägglund AC, Dahl L, Carlsson L (2011) Lhx2 is required for patterning and expansion of a distinct progenitor cell population committed to eye development. PLoS One 6:e23387. CrossRef Medline

Hatini V, Huh SO, Herzlinger D, Soares VC, Lai E (1996) Essential role of stromal mesenchyme in kidney morphogenesis revealed by targeted disruption of Winged Helix transcription factor BF-2. Genes Dev 10:14671478. CrossRef Medline

Hsieh J (2012) Orchestrating transcriptional control of adult neurogenesis. Genes Dev 26:1010-1021. CrossRef Medline

Humphreys BD, Valerius MT, Kobayashi A, Mugford JW, Soeung S, Duffield JS, McMahon AP, Bonventre JV (2008) Intrinsic epithelial cells repair the kidney after injury. Cell Stem Cell 2:284-291. CrossRef Medline

Langlet F, Levin BE, Luquet S, Mazzone M, Messina A, Dunn-Meynell AA, Balland E, Lacombe A, Mazur D, Carmeliet P, Bouret SG, Prevot V, Dehouck B (2013) Tanycytic VEGF-A boosts blood-hypothalamus barrier plasticity and access of metabolic signals to the arcuate nucleus in response to fasting. Cell Metab 17:607-617. CrossRef Medline

Lechan RM, Fekete C (2007) Infundibular tanycytes as modulators of neurodendocrine function: hypothetical role in the regulation of the thyroid and gonadal axis. Acta Biomed 78 [Suppl 1]:84-98. Medline

Lee DA, Blackshaw S (2012) Functional implications of hypothalamic neu- rogenesis in the adult mammalian brain. Int J Dev Neurosci 30:615-621. CrossRef Medline

Lee DA, Blackshaw S (2014) Feed your head: neurodevelopmental control of feeding and metabolism. Annu Rev Physiol 76:197-223. CrossRef Medline

Lee DA, Bedont JL, Pak T, Wang H, Song J, Miranda-Angulo A, Takiar V, Charubhumi V, Balordi F, Takebayashi H, Aja S, Ford E, Fishell G, Blackshaw S (2012) Tanycytes of the hypothalamic median eminence form a diet-responsive neurogenic niche. Nat Neurosci 15:700-702. CrossRef Medline

Lee DA, Salvatierra J, Velarde E, Wong J, Ford EC, Blackshaw S (2013) Functional interrogation of adult hypothalamic neurogenesis with focal radiological inhibition. J Vis Exp 81:e50716. CrossRef Medline

Lee DA, Yoo S, Pak T, Salvatierra J, Velarde E, Aja S, Blackshaw S (2014) Dietary and sex-specific factors regulate hypothalamic neurogenesis in young adult mice. Front Neurosci 8:157. CrossRef Medline

Lu F, Kar D, Gruenig N, Zhang ZW, Cousins N, Rodgers HM, Swindell EC, Jamrich M, Schuurmans C, Mathers PH, Kurrasch DM (2013) Rax is a selector gene for mediobasal hypothalamic cell types. J Neurosci 33:259272. CrossRef Medline

Mangale VS, Hirokawa KE, Satyaki PR, Gokulchandran N, Chikbire S, Subramanian L, Shetty AS, Martynoga B, Paul J, Mai MV, Li Y, Flanagan LA, Tole S, Monuki ES (2008) Lhx2 selector activity specifies cortical identity and suppresses hippocampal organizer fate. Science 319:304-309. CrossRef Medline

Merkle FT, Tramontin AD, García-Verdugo JM, Alvarez-Buylla A (2004) Radial glia give rise to adult neural stem cells in the subventricular zone. Proc Natl Acad Sci U S A 101:17528-17532. CrossRef Medline

Millhouse OE (1971) A Golgi study of third ventricle tanycytes in the adult rodent brain. Z Zellforsch Mikrosk Anat 121:1-13. CrossRef Medline

Millhouse OE (1972) Light and electron microscopic studies of the ventricular wall. Z Zellforsch Mikrosk Anat 127:149-174. CrossRef Medline

Ming GL, Song H (2011) Adult neurogenesis in the mammalian brain: significant answers and significant questions. Neuron 70:687-702. CrossRef Medline

Miranda-Angulo AL, Byerly MS, Mesa J, Wang H, Blackshaw S (2014) Rax regulates hypothalamic tanycyte differentiation and barrier function in mice. J Comp Neurol 522:876-899. CrossRef Medline

Monuki ES, Porter FD, Walsh CA (2001) Patterning of the dorsal telencephalon and cerebral cortex by a roof plate-Lhx2 pathway. Neuron 32:591604. CrossRef Medline

Mullier A, Bouret SG, Prevot V, Dehouck B (2010) Differential distribution of tight junction proteins suggests a role for tanycytes in bloodhypothalamus barrier regulation in the adult mouse brain. J Comp Neurol 518:943-962. CrossRef Medline

Pak T, Yoo S, Miranda-Angulo AM, Wang H, Blackshaw S (2014) RaxCreER ${ }^{\mathrm{T} 2}$ knock-in mice: a tool for selective and conditional gene deletion in progenitor cells and radial glia of the retina and hypothalamus. PLoS One 9:e90381. CrossRef Medline

Pearson CA, Placzek M (2013) Development of the medial hypothalamus: forming a functional hypothalamic-neurohypophyseal interface. Curr Top Dev Biol 106:49-88. CrossRef Medline

Pierce AA, Xu AW (2010) De novo neurogenesis in adult hypothalamus as a compensatory mechanism to regulate energy balance. J Neurosci 30:723730. CrossRef Medline

Porter FD, Drago J, Xu Y, Cheema SS, Wassif C, Huang SP, Lee E, Grinberg A, Massalas JS, Bodine D, Alt F, Westphal H (1997) Lhx2, a LIM homeobox gene, is required for eye, forebrain, and definitive erythrocyte development. Development 124:2935-2944. Medline

Rhee H, Polak L, Fuchs E (2006) Lhx2 maintains stem cell character in hair follicles. Science 312:1946-1949. CrossRef Medline

Richter K, Wirta V, Dahl L, Bruce S, Lundeberg J, Carlsson L, Williams C (2006) Global gene expression analyses of hematopoietic stem cell-like cell lines with inducible Lhx2 expression. BMC Genomics 7:75. CrossRef Medline

Robins SC, Stewart I, McNay DE, Taylor V, Giachino C, Goetz M, Ninkovic J, Briancon N, Maratos-Flier E, Flier JS, Kokoeva MV, Placzek M (2013) $\alpha$-Tanycytes of the adult hypothalamic third ventricle include distinct populations of FGF-responsive neural progenitors. Nat Commun 4:2049. CrossRef Medline

Rodríguez EM, Blázques JL, Pastor FE, Paláez B, Peña P, Peruzzo B, Amat P 
(2005) Hypothalamic tanycytes: a key component of brain-endocrine interaction. Int Rev Cytol 247:89-164. CrossRef Medline

Roy A, de Melo J, Chaturvedi D, Thein T, Cabrera-Socorro A, Houart C, Meyer G, Blackshaw S, Tole S (2013) LHX2 is necessary for the maintenance of optic identity and for the progression of optic morphogenesis. J Neurosci 33:6877-6884. CrossRef Medline

Sánchez E, Vargas MA, Singru PS, Pascual I, Romero F, Fekete C, Charli JL, Lechan RM (2009) Tanycyte pyroglutamyl peptidase II contributes to regulation of the hypothalamic-pituitary-thyroid axis through glialaxonal associations in the medial eminence. Endocrinology 150:22832291. CrossRef Medline

Shimada M, Nakamura T (1973) Time of neuron origin in mouse hypothalamic nuclei. Exp Neurol 41:163-173. CrossRef Medline

Shimogori T, Lee DA, Miranda-Angulo A, Yang Y, Wang H, Jiang L, Yoshida AC, Kataoka A, Mashiko H, Avetisyan M, Qi L, Qian J, Blackshaw S (2010) A genomic atlas of mouse hypothalamic development. Nat Neurosci 13:767-775. CrossRef Medline
Soriano P (1999) Generalized lacZ expression with the ROSA26 Cre reporter strain. Nat Genet 21:70-71. CrossRef Medline

Stubbs JL, Oishi I, Izpisúa Belmonte JC, Kintner C (2008) The forkhead protein Foxj1 specifies node-like cilia in Xenopus and zebrafish embryos. Nat Genet 40:1454-1460. CrossRef Medline

Xu Q, Tam M, Anderson SA (2008) Fate mapping Nkx2.1-lineage cells in the mouse telencephalon. J Comp Neurol 506:16-29. CrossRef Medline

Yu X, Ng CP, Habacher H, Roy S (2008) Foxj1 transcription factors are master regulators of the motile ciliogenic program. Nat Genet 40:14451453. CrossRef Medline

Yun S, Saijoh Y, Hirokawa KE, Kopinke D, Murtaugh LC, Monuki ES, Levine EM (2009) Lhx2 links the intrinsic and extrinsic factors that control optic cup formation. Development 136:3895-3906. CrossRef Medline

Zhao Y, Mailloux CM, Hermesz E, Palkóvits M, Westphal H (2010) A role of the LIM-homeobox gene Lhx2 in the regulation of pituitary development. Dev Biol 337:313-323. CrossRef Medline 